\title{
Entre el naturalismo y la tradición. Un estudio comparativo entre la propuesta pedagógica de los ilustrados españoles y Rousseau
}

\author{
Sebastián Perrupato \\ UNMdP - CONICET
}

\begin{abstract}
Resumen:
Dos interpretaciones han marcado la historiografía sobre la Ilustración española, por un lado aquella que marcaba que todo lo nuevo, vivificante y trascendente provenía del influjo francés, y por otro aquella que sostenía que la originalidad de la misma estaba dada por su componente católico.

El presente trabajo intenta analizar de modo comparativo la pedagogía roussoniana y las propuestas pedagógicas de los ilustrados españoles. Partiendo de la consideración de que ni todo lo nuevo procede del influjo francés, ni la originalidad está dada por el componente católico de la Ilustración, sino que las propuestas españolas forman parte de un complejo sistema de "circulación de ideas", en el que no sólo se retoman elementos de la Ilustración europea y se los re significa, sino que también se originan los propios.
\end{abstract}

Palabras Claves: Educación - Ilustración española - Rousseau - Circulación de ideas

\begin{abstract}
:
Two interpretations have marked the historiography of the Spanish Enlightenment, first one that marked that everything new, crisp and important influence came from the French, and another who argued that the originality of it was given by its Catholic component.

This paper attempts a comparative analysis of Rousseau's pedagogy and pedagogical proposals of the Spanish Enlightenment. Based on the consideration that not everything new comes from the French influence, nor originality is given by the Catholic component of the Enlightenment, but the Spanish proposals are part of a complex system of "movement of ideas", in which no only takes up elements of the European Enlightenment and the re means, but also originate themselves.
\end{abstract}

Key Words: Education - Spanish Enlightenment - Rousseau - Circulation of ideas

PERRUPATO, Sebastián, "Entre el naturalismo y la tradición. Un estudio comparativo entre la propuesta pedagógica de los ilustrados españoles y Rousseau", en Avances del Cesor, Año IX, N 9, 2012, pp. 175-194. 


\section{Introducción}

En toda clase de proyecto hay que considerar dos cosas: primeramente, la bondad absoluta del proyecto; en segundo lugar, la facilidad de la ejecución. Respecto al primer extremo, es suficiente, para que el proyecto sea admisible y practicable en sí mismo, que cuanto tenga de bueno esté en la naturaleza de la cosa; aquí, por ejemplo, que, la educación propuesta sea conveniente al hombre, y bien adaptada al corazón humano. La segunda consideración depende de las relaciones dadas en determinadas situaciones: relaciones accidentales a la cosa, las cuales como consecuencia, no son necesarias y pueden variar al infinito. De esta forma, tal educación puede ser practicable en Suiza y no serlo en Francia. ${ }^{1}$

Sin dudas, Rousseau ha quedado en la historia del pensamiento europeo como uno de los mayores intelectuales franceses. No cabe dudas tampoco, de lo esencial de su pensamiento para la pedagogía contemporánea, su figura fue muy trabajada desde la historia de la educación dado que su impronta revolucionaria servirá de base para las nuevas corrientes pedagógicas.

El cruce entre las propuestas pedagógicas de los ilustrados europeos ha generado interesantes estudios que intentan vincular la pedagogía española de fines de siglo XVIII con las ideas pedagógicas que impregnaban los aires europeos y generaban nuevo influjo a la educación. ${ }^{2}$ Sin embargo, muchos de estos análisis repiten el planteo de la historiografía tradicional que intenta ver en la ilustración española la copia de la francesa. ${ }^{3}$

El presente trabajo tiene por objetivo comparar la propuesta pedagógica roussoniana con la que desarrollaron los ilustrados españoles, en un contexto algo distinto al del resto de Europa, dada la impronta religiosa de una sociedad que, aún en el siglo XVIII, se negaba a abandonar los cánones cristianos que daban fundamento a una sociedad estamental en evidente crisis.

En este ambiente, parece contradictorio pensar que entre los ilustrados españoles adquiera relevancia un corpus de ideas revolucionario como el rousseauniano. Pensar en la corriente filosófica deísta a la que adscribía y llevarla a un contexto español católico a ultranza puede parecer erróneo si no se tienen en cuenta otros factores.

1 ROUSSEAU, Jean-Jacques, Emilio o de la educación, Edaf, Bs. As, 2008 (1762), p. 33

2 Sobre el tema se recomienda ver el estado de la cuestión que ha realizado: LAZARO LLORENTE, Luis, "La revolución francesa y su influencia en la ecuación española". Revista de educación, N 300, pp. 399-403. Ver también: RODRÍGUEZ ARANDA, Luis, "La influencia en España de las ideas pedagógicas de John Locke”, Revista de pedagogía. Madrid, XXIV, N 47, 1954. 321-327. OSSENBACH SAUTER, Gabriela y PUELLES BENÍTEZ, Manuel (eds.), La Revolución francesa y su influencia en la educación en España, UNED, Madrid, 1991.

3 SARRAILH, Jean, La España ilustrada de la segunda mitad del siglo XVIII, Fondo de Cultura Económica, México, 1957. 
Ante una España en crisis la respuesta invariable fue la reforma. No obstante, la reforma que profesaban los ilustrados europeos era, en muchos casos, demasiado revolucionaria para una sociedad que creía firmemente en la tradición. En este marco, la educación también debía reformarse y es ahí donde se suscitan diversas propuestas por momentos contradictorias y enfrentadas.

Pareciera que el análisis que muchos de los ilustrados españoles hacen de Rousseau va en paralelo de su visión política y cívica. Toman aspectos pedagógicos que intentan integrar a una sociedad tradicional, sin tener en cuenta que la propuesta del francés es una propuesta integral, que el Emilio se completa con el Contrato Social, y que su visión educativa trasciende el ámbito pedagógico para influir en la sociedad transformándola en una utopía.

Sin embargo, éste no es el análisis de todos los ilustrados españoles. Algunos llevaban la propuesta educativa un poco más allá, viendo en la educación una herramienta para transformar la sociedad existente y planteando un ideal de reforma más próximo al roussoniano.

De esta manera el cruce entre las obras de Rousseau y la de otros ilustrados españoles nos acerca a una visión panóptica de la Ilustración española, entendiéndola desde la Histoire Croisée, ${ }^{4}$ y comprendiendo que la misma no es ajena a las propuestas que se suscitan en el mundo, retomando conceptos e ideas y exportando las propias. En este sentido entendemos que la apropiación de los discursos no consiste en la aceptación sistemática de las otras propuestas, sino en la asimilación y adaptación de aquellas que son funcionales al contexto en el que se encuentran inmersas. ${ }^{5}$

\section{La propuesta pedagógica de Rousseau entre el naturalismo y la revolución}

Rousseau nació en Ginebra en $1712,{ }^{6}$ poco es lo que se sabe de su vida posterior salvo que su madre murió al nacer y que su padre debió exiliarse dejándolo al cuidado de su tío, quien encomendó su educación a un pastor evangélico. Para 1750, redacta su Discurso sobre las ciencias y las artes con el cual logra fama y prestigio. Sin embargo, habrá que esperar hasta 1762 para que sus obras más importantes salgan a la luz; durante este año

4 WERNER, Michael. y ZIMMERMANN, Benedicte, "Beyond comparison: Histoire Croisée and the challenge of reflexivity", en History and Theory $\mathrm{N}^{\circ} 45,2006$, pp. 30-50.

5 El tema de la apropiación ha sido bastante trabajado por Michael Foucault y retomado desde la historia por Roger Chartier. Al respecto se puede consultar: CHARTIER, Roger, El Mundo como Representación. Historia Cultural: entre práctica y representación. Editorial Gedisa, Barcelona, 1992, pp. 45-62.

6 Algunos autores intentan ver en este origen ginebrino el elemento para negar la nacionalidad francesa a Rousseau, sin embargo, desde los 16 años pasó su vida en Francia, en el pueblo de Annecy primero, Montpellier y Lyon después, asentándose en París a los 33 años donde permaneció hasta su exilio en 1765. 
publica El Contrato Social (tratado político) y el Emilio (tratado pedagógico) de los cuales se desprende toda su doctrina pedagógica. Este último ha sido valorado, no solo por la crítica contemporánea sino también por él mismo, como el mejor y más útil de sus escritos. ${ }^{7}$

Pero su publicación no fue del todo bien recibida en su tiempo, por el contrario, provocó duras críticas por parte de la Iglesia y el gobierno civil -especialmente aquellas páginas dedicadas a la profesión de fe del Vicario saboyano y el Arzobispo de París- que lo obligarían a dejar la ciudad francesa terminando sus días de exilio en Inglaterra donde Hume le brinda hospitalidad. Quizás debido a esto la popularidad que alcanzó Rousseau no condujo a que sus ideas fueran aceptadas y aplicadas a la educación de inmediato en Europa.

Posiblemente el éxito de Rousseau se deba a la originalidad de haber pensado la educación como una nueva fórmula para un mundo que había iniciado un proceso histórico de dislocación política-social. Su obra es un punto de convergencia de grandes corrientes de la época, donde se enfrentan teorías que no han dejado de gestar el pensamiento occidental desde la antigüedad.

Si bien el autor se enmarca en el ámbito de la Ilustración, su pensamiento no se orienta en total acuerdo con las teorías del racionalismo, por el contrario, se vuelca hacia el subjetivismo y la espontaneidad emocional del naturalismo, es decir, el retorno del hombre a la naturaleza. El tema del naturalismo pedagógico del ilustrado francés ha suscitado varias contradicciones y discusiones, sin embargo, podemos afirmar -como lo hace Luzuriagaen que el naturalismo al que hace referencia el autor es un naturalismo en cierto sentido humanista:

La naturaleza es lo primordial en la teoría de la educación roussoniana; pero la naturaleza se interpreta en ella de diversos modos... Rousseau busca al hombre primitivo, natural y anterior a todo lo social. Pero ello es solo el aspecto externo y negativo de la naturaleza. Lo primitivo y valioso en esta es la naturaleza como equivalente a lo esencial del hombre, lo que tiene un valor sustantivo y permanente. El este sentido hay que hablar más del humanismo que del naturalismo de Rousseau. ${ }^{8}$

El desarrollo natural tiene sus propias leyes, para que Emilio sea realmente libre no se lo puede dejar al libre albedrío de la naturaleza, porque está destinado a vivir en sociedad.

La infancia ya no aparece en él como un estadio de preparación para ser adulto, sino que es un estado especial con su propio equilibrio, sus propias leyes y reglas; la naturaleza es la maestra perfecta y el hombre debe amoldarse a ella. El niño nace en una sociedad y aparece destinado a vivir con sus semejantes, en este sentido pareceria necesario aislarlo ${ }^{9}$ en el momento del nacimiento y ponerlo bajo el cuidado de un preceptor cuidadosamente

7 Ver por ejemplo sus Confesiones (1770) y Ensoñación del paseante solitario (1776).

8 LUZURIAGA, Lorenzo, Historia de la educación y de la pedagogía, Losada, Bs. As., 1980, p. 166

9 Concepto en boga a partir de la epistemología lockeana 
escogido. ${ }^{10}$ Sólo estimulando al niño desde pequeño, se podria lograr una manera de comprender y valorar la existencia conforme a la naturaleza. En palabras del autor:

Se opina que los niños en libertad pueden adquirir malas posiciones y hacer movimientos que perjudiquen a la buena conformación de sus miembros. Éste es uno de los tantos vanos razonamientos de nuestra falsa sabiduría, y que ninguna experiencia ha confirmado. ${ }^{11}$

La naturaleza ha fijado etapas necesarias para el desarrollo y desenvolvimiento corporal y anímico del educando, principio llamado "ley de sucesión genética". El Emilio se divide según los diferentes estadios en la vida del protagonista y en consonancia con su desarrollo biológico trata su aprendizaje.

Desde que el niño nace, la educación debe ocuparse de lo concerniente a los sentimientos, y en este sentido el rol de la madre es esencial durante esta etapa; después desde los 2 hasta los 12 años el niño debe aprender a juzgar y valorar las cosas que se le ofrecen, ganando cada vez más la conciencia de libertad; posteriormente entre los 12 y 15 años la experiencia de la realidad debe orientarse mediante preguntas encaminadas a despertar la curiosisdad del niño, siendo los intereses los que determinen la enseñanza; entre los $15 \mathrm{y}$ 20 años Emilio debe iniciarse en los sentimientos de la amistad y la piedad, siendo los 18 años la edad propicia para comenzar a hablar de Dios, justo en el momento en que el estado sexual comienza a despertarse para pensar en la necesidad de una compañera.

Luego de los 20 años, podría conseguir la compañía de una mujer cuyas características son quizás el punto más enervado de la doctrina roussoniana. ${ }^{12}$ Sofía es el nombre de la mujer elegida para acompañar a Emilio en su vida, la formación de ella es el paradigma de la educación femenina, dada a partir de la subordinación al hombre:

Un determinismo natural gobierna el mundo femenino; su finalidad es ser esposa y madre, agradar al hombre y darle hijos. La fuerza de la mentalidad burguesa, que reintegra a la mujer al hogar, al servicio del hombre, pero elevándola al nivel de compañera, y que reivindica el matrimonio por amor y la intimidad familiar. ${ }^{13}$

10 IGLESIAS, María. "Prologo", en ROUSSEAU, Jean-Jacques, Emilio ..., Op. Cit.

11 ROUSSEAU, Jean-Jacques, Emilio ..., Op Cit. p. 44.

12 No es nuestra intención realizar un estudio de género sobre el tema, ni detenernos en la problemática de la mujer en la ilustración. Si retomamos este aspecto en la obra del ilustrado es solo a los efectos de la comparabilidad que este tiene con otros ilustrados españoles. Sobre el lugar de la mujer en la obra de Rousseau se pueden consultar: CALDERÓN QUINDÓS, Fernando: "La mujer en la obra de Jean-Jacques Rousseau", Revista de Filosofía, 2005, vol. 30, № 1, pp. 165-177. VALENZUELA VILA María del Mar "La educación en el Emilio de Rousseau: infancia, adolescencia y mujer", Espéculo. Revista de estudios literarios. Universidad Complutense de Madrid. 2009.

13 IGLESIAS, María, "Prólogo", en ROUSSEAU, Jean-Jacques, Emilio..., Op. Cit., p.21 
Tradicionalmente los cientistas sociales han juzgado y criticado el papel de la mujer en la obra de Rousseau como algo que contradice y anula la libertad y los avances que se generan desde su propuesta. Sin embargo, a nuestro entender, el papel de la mujer es por demás coherente con la propuesta educativa que hace lo que propone es un programa de educación femenina que eduque para la familia. Como dice María del Carmen Iglesias: es el "modelo de familia burguesa" 14 que rompe con el modelo clásico, en el que las madres no se hacían cargo de sus hijos y lo entregaban en manos de amas o prelados. En este sentido es que consideramos que la obra no es contradictoria con su pensamiento, sino que responde a un contexto histórico social distinto, así como a un modelo pedagógico que se inicia en los primeros años de la infancia y en el cual la madre debe ocupar un lugar destacado en la educación de los niños.

La educación para el trabajo es esencial en la pedagogía de Rousseau la educación de los tutorados en un oficio tiene por fin, resguardar a los mismos de la desgracia. En este sentido debemos recordar la necesidad del tutor del Emilio de educarlo en las "artes prácticas", es decir, en un oficio que lo prepare para la vida:

Poco me importa si mi alumno esté destinado a la espada, a la Iglesia, al foro. Antes que la vocación de los padres, la naturaleza lo reclama para la vida Humana. Vivir es el oficio que quiero enseñarle. Al salir de mis manos no será convengo en ello, ni magistrado, ni soldado, ni sacerdote; Será hombre ante todo: todo lo que el hombre debe ser, sabrá serlo, en caso necesario tan bien como cualquiera; y por más que la fortuna le haga cambiar de lugar, el siempre estará en lo suyo. ${ }^{15}$

Nos queda pues, en este breve recorrido, hacer referencia a la educación positiva y negativa que propugna el autor. Anteriormente hemos mencionado que la educación del niño debía ser gradual, es decir, según los estadios propios de la naturaleza, en este sentido el educador debe saber acompañar el desarrollo del niño e intervenir lo menos posible en este proceso de aprendizaje. Siendo así, que la educación humana debe ser negativa hasta los 12 años, si se introduce en esta edad el error y el vicio será muy difícil extraerlo después, el tutor debe preservarse al niño del error sin enseñar principio alguno.

Este concepto no excluye la dirección del maestro. Rousseau entiende la educación negativa como una educación indirecta no como la inactividad del educador. No se trata de que el alumno haga lo que quiera de modo absoluto, sino de controlar indirectamente su ambiente, sus experiencias, sus compañías, sus juegos, sin pretender llevar a cabo una instrucción de la que no podría beneficiarse.

Llamo Educación Positiva la que tiende a formar prematuramente el espíritu del niño, y ha de instruirle en los deberes que corresponden al hombre. Y llamo Educación

14 Ibídem.

15 ROUSSEAU, Jean-Jacques, Emilio..., Op. Cit., Libro I. 
Negativa a la que tiende a perfeccionar los órganos, que son los instrumentos del conocimiento, antes de darle contenido alguno, y que procura preparar el camino a la razón por el ejercicio adecuado de los sentidos. Una educación negativa no supone un período de pereza. No da ninguna virtud, pero protege del vicio; no inculca la verdad, pero protege del error. Prepara al niño para que siga el camino de la verdad, cuando llegue a la edad de comprenderla; y el de la bondad, cuando pueda reconocerla y amarla. ${ }^{16}$

En síntesis, Rousseau vela por una educación integral, total, libre, gradual natural y humana. Es un proyecto político revolucionario que se inicia con El Contrato Social y se cierra con el Emilio. La educación que propone es una educación utópica que poca aplicación tiene en la práctica. ${ }^{17}$ Pretende educar en un radical individualismo de modo que cuando se haya logrado un pleno autodominio, pueda el individuo entregarse a la voluntad general. La sociedad que desea Rousseau no es la suma de voluntades individuales, sino la anulación de toda afirmación y deseo individual en pos de una construcción mayor.

La educación de la naturaleza, que programa Rousseau es idílica y es contradictoria con la esencia misma del ser social, siendo la no superación de esta contradicción la fuente de todos los males pedagógicos, sociales y morales, ser un hombre sin contradicción interna (ideal que el mismo no puede alcanzar) es el objetivo educativo de Rousseau. ${ }^{18}$

\section{España Ilustrada ¿Copia francesa o originalidad nacional?}

La historiografía tradicional, argumentaba que el menesteroso nivel intelectual de las últimas décadas del Siglo XVII se prolonga durante las primeras décadas del XVIII. Se ha concebido el reinado de Felipe $\mathrm{V}$ como un desierto intelectual en el que aparece y se alza solitaria la figura de Benito Jerónimo Feijoo. Sin embargo. durante los últimos años esta concepción se ha matizado, argumentando que desde fines del siglo XVII comienzan a expandirse como en el resto de Europa, nuevas orientaciones científico-filosóficas. ${ }^{19}$

Las nuevas ideas no hallaban su lugar en las aulas monásticas ni en los claustros universitarios, dominados por los peripatéticos. Su lugar de desarrollo fueron las tertulias sostenidas por los grandes magnates, sin duda, la más importante fue la de Sevilla. ${ }^{20}$ Aferrados a los

16 Ídem, Libro V.

17 El mismo Rousseau habría recriminado a un admirador suyo por someter a sus hijos a las normas expuestas en su obra.

18 SPAEMAN, Robert, Rousseau - Mensch oder Bürger, Stuttgart, 2008.

19 Hugo de O Manrique, comerciante extranjero en la bahía de Cádiz publica su libro "Análisis geométrico", obra alabada por Newton; Juan Cabriada en Madrid, en 1687, hace lo mismo con "Cartas filosóficas, medico-Chynica" en las que demuestra estar al corriente de los adelantos europeos; se destaca también un grupo de matemáticos en Valencia: Zaragoza, Tosca y Corachan.

20 Pese a su decadencia, esta ciudad, mantenía amplios contactos exteriores al punto de crear en 
principios tradicionales y convencidos de que toda novedad por el mero hecho de ser nueva era falsa y peligrosa, los escolásticos llamaban a sus adversarios Novadores o Novatores.

En este contexto la aparición de las obras de Feijoo se ubicaban dentro de una lucha contra la España obscurantista y venía a "desengañar al vulgo de las supersticiones"21, es decir, a realizar una crítica racional y empírica, buscando la erradicación del error. Así su "Teatro Crítico Universal" y sus "Cartas Eruditas" son una síntesis de modernismo y tradición, se encuentran a caballo entre lo viejo y lo nuevo, defendiendo cuestiones que tienden a la conservación del orden, pero incluye otras más modernas relacionadas con las nuevas ideas de la sociedad.

Pero la figura de Feijoo no es la única que aparece como charnela entre estos dos puntos, otras figuras importantes adquieren relevancia durante el siglo, entre ellas destacan Martí, Miñana, Mariana, Enrique Flores y Gregorio Mayans ${ }^{22}$ quien discutiría abiertamente con Feijoo, pese a que su obra adquirirá especial relevancia después de la primera mitad del siglo XVIII

En este contexto aceptar que la llegada de la Ilustración a España aparece en un contexto de desierto intelectual donde la apropiación se da como resultado de la necesidad de llenar este vacío, puede resultar equivoco. Por el contrario, la rica tradición previa a la Ilustración forma la base que definió la dirección y el sentido de la apropiación española del pensamiento europeo.

En este sentido cabe preguntarnos: ¿En qué medida España se vió influida por el movimiento de las luces? ¿Es cierto que a España le ha faltado su gran siglo Educador y que todo lo nuevo en esta materia ha sido importado del resto de Europa? Estas dos preguntas han desvelado a muchos intelectuales españoles que se han preocupado por encontrar en las particularidades españolas respuestas a estos interrogantes. Así muchos entendieron que la originalidad de la Ilustración española estaba dada por su talante católico. ${ }^{23} \mathrm{Sin}$ embargo, si analizamos las propuestas pedagógicas, advertimos que ya en la primera mitad del siglo XVIII francés, se alzaba la figura del educador Carlos Rollin quien propugnaba una educación católica amparada en el catecismo histórico de Fleury, ${ }^{24}$ obra que será retomada posteriormente en España por otros ilustrados como por ejemplo, Clavijo y Fajardo.

1697 la "Sociedad de Medicina de Sevilla".

21 MESTRE, Antonio, Despotismo e ilustración en España; Barcelona, Ariel, 1976, pp. 35

22 Al respecto pueden consultarse: FLORES, Enrique, La España Sagrada; MAYAS, Vida de Miguel de Cervantes Saavedra, España primitiva; La continuación de Historia de Rebus Hispaniae (1730) de MARIANA por su discípulo MIÑANA y De bello rustico valentino (1752).

23 MESTRE, Antonio, La Ilustración, Sintesis, Madrid, 1993 o La Ilustración española, Arco, Madrid, 1998.

24 Sobre el tema se puede consultar: MORENO, Juan, POBLADOR, Alfredo, DEL RIO, Dionisio, Historia de la Educación. BIE, Madrid, 1971. 
En este sentido, aceptamos que la llegada de los Borbones a España trajo como consecuencia un mayor contacto con otras naciones, así como un mayor conocimiento del pensamiento pedagógico europeo. Historiadores como Américo Castro nos dicen:

Al llegar el siglo XVIII España se incorporó a Europa, se emparejó con ella Los reflejos españoles de la ilustración fueron tenues y no afectaron al hombre consigo mismo, con la sociedad con Dios y con la naturaleza La herejía de algunos intelectuales a fin de siglo XVIII era el simple eco de lo pensado fuera de España. Espontáneamente los españoles no tenían nada propio con qué reemplazar sus creencias, en algunos casos, se limitaban a reaccionar violentamente contra ellos. ${ }^{25}$

Por otro lado, pensadores más conservadores han analizado el fenómeno desde una perspectiva diferente, Menéndez Pelayo escribía por ejemplo:

La revolución triunfante ha divinizado a sus ídolos y enaltecido a cuantos le prepararon fácil camino; sus nombres, los de Aranda, Floridablanca, Campomanes, Roda, Cabarrús, Quintana Viven en la memoria y en la lengua de todos; no importa su mérito en absoluto; basta que sirviesen a la revolución, cada cual en su esfera; todo lo demás del siglo XVIII ha quedado en su sombra. ${ }^{26}$

A su vez Ramiro de Maeztu entiende que: "La raíz de la revolución de España, allá en los comienzos del siglo XVIII, ha de buscarse únicamente en nuestra admiración del extranjero. No brotó de nuestro ser, sino de nuestro no ser". ${ }^{27}$

En este orden de ideas, no proponemos que la educación durante la Ilustración española fue la aceptación sistemática de todos los preceptos externos (roussonianos, lockeanos, entre otros), ni tampoco la originalidad manifiesta que enarbolaba las ideas de una educación católica, sino un complejo fenómeno de intercambios culturales, con ideas y pensamientos que circularon en ambas direcciones, aunque, una dirección es notoriamente más marcada.

Pierre Bourdieu ha trabajado con el concepto de "circulación de ideas" 28 que parece oportuno aplicar aquí. Por "circulación de ideas" se entiende el proceso de emisión y recepción de las ideas desde unas regiones hacia otras, asumiendo que en este transcurso se van

25 CASTRO, Américo, Los españoles, cómo llegaron a serlo, Taurus, Madrid, 1965, pp. 138-139. 26 MENENDEZ PELAYO, Marcelino, Historia de los heterodoxos españoles, Editorial Nacional, Madrid, 1956. T. II, p. 667.

27 MAEZTU, Ramiro, Defensa de la Hispanidad, Rialp, Madrid, 1952, p. 18.

28 BOURDIEU, Pierre, "Las condiciones sociales de la circulación internacional de ideas", Conferencia 30 de octubre 1989 para la inauguración de Frankreich-Zentrum de la Universidad de Friburgo. Publicado en: Diario de la Historia de la literatura romántica, 1990. pp. 1-10. 
produciendo mutaciones o hibridaciones ${ }^{29}$ y que "el significado y la función de las obras extranjeras son determinadas tanto por el campo de acogida como por el campo original" ${ }^{30}$

El análisis del cuál partimos para la realización del presente trabajo pretende entonces acercar el pensamiento ilustrado español al pensamiento pedagógico roussoniano en clave comparativa, entendiendo que forman parte de un proceso más amplio de "Circulación de ideas", propio del pensamiento de un siglo profundamente ecléctico. En este sentido, lo entendemos como un proceso de apropiación de ideas en diferentes direcciones en el cual la apropiación que los ilustrados españoles tienen de ideas pedagógicas europeas, responde siempre a la lectura que, con un contexto e intereses diferentes, hicieron los españoles. ${ }^{31}$

\section{Cruzando fronteras, comparando destinos. La propuesta de Rousseau en la pedagogía española dieciochesca}

Muchos de los ilustrados españoles han leído e incluso se han carteado con Jean-Jaques Rousseau, sin embargo, como mencionamos anteriormente, el acercamiento a este intelectual pudo haber sido encausado en dos direcciones: en primer lugar encontramos aquellos ilustrados españoles que parecen no haber entendido que la propuesta roussoniana era utópica y revolucionaria. La mayor parte de estos intelectuales no dudaron en utilizar ideas del autor sin haber comprendido que las dos obras de 1762 forman un todo y que El Contrato Social debiera considerarse como una especie de apéndice al tratado de educación. ${ }^{32}$ En una segunda dirección, podemos situar a los ilustrados que aceptaban este postulado pedagógico como parte de un todo, manteniendo en sus escritos un talante más jacobino y revolucionario.

A continuación analizaremos algunas de las propuestas ilustradas que se han apropiado de las ideas circulantes y las han reelaborado en función del interés y contexto. Los autores analizados han sido de gran importancia para la época, tanto dentro como fuera de la

29 El concepto de "hibridismo cultural" ha sido trabajado por Peter Burke quien entiende que se trata de un encuentro cultural. Encuentro, que implica no solo bilateralidades simétricas sino también fusiones, sincretismos, adaptaciones, circularidades, traducciones, segregaciones y resistencias. El termino aparece así "escurridizo y ambiguo al mismo tiempo literal y metafórico, descriptivo y explicativo" BURKE Peter, Hibridismo cultural, Editorial Akal, Madrid, 2010.

30 BOURDIEU, Pierre, "Las condiciones...", Op. Cit., p 3.

31 Para Roger Chartier la apropiación apunta a una historia social de usos e interpretaciones fundamentales inscritas en las prácticas específicas que los producen. Se trata de prestar atención a las condiciones y a los procesos que llevan las operaciones de construcción del sentido es reconocer, en contra de la antigua historia intelectual, que ni las inteligencias ni las ideas son descarnadas, y contra los pensamientos de lo universal, que las categorías dadas como invariables, ya sean filosóficas o fenomenológicas, deben construirse en la discontinuidades las trayectorias históricas. Ver: CHARTIER, Roger, El Mundo ..., Op. Cit.

32 Correspondance generale de Jean-Jaques Rousseau. Paris. 1924-1934, V. VII, p. 233.

\section{4}


península. Sin embargo, no podemos obviar el detalle, para nada menor, que implican los ámbitos de circulación de sus producciones. Así, si bien existen algunos de mayor popularidad, otros se han movido más en la esfera privada y sus producciones no han sido de gran difusión dentro del público en general.

\section{Primera infancia y educación materna: Clavijo y Fajardo}

Si bien el tema de la primera infancia ha sido una preocupación común a casi todos los ilustrados españoles, Clavijo y Fajardo ha sido uno de los que más se ha dedicado al tema. Este intelectual abreva en varios autores tanto ingleses como franceses, aunque desde el aspecto pedagógico tiene una clara dependencia con Locke y Rousseau. Con respecto a su dependencia roussoniana ha escrito Espinosa:

El hecho de ser coetáneas las obras de Clavijo y Rousseau y de escribir ambos bajo la inmediata influencia de los pensamientos de pedagogía lockianos parece indicar que las semejanzas, que entre los escritos de uno y otro se advierten, tienen por única causa el ser una misma fuente la que alimentó las obras de ambos escritores. No es así, sin embargo. La influencia de Rousseau en la obra pedagógica de Clavijo es innegable, y si las analogías que con relación a la educación de los niños se encuentran en ambos responden a la causa anteriormente supuesta, no sucede lo mismo en lo que responde a la educación femenina. ${ }^{33}$

En este sentido, es innegable la influencia roussoniana, en el discurso que el autor tiene acerca de la mujeres, según Espinosa, la teoría feminista de Clavijo no es más que la traducción de algunos párrafos de Sophie. Este pensamiento ha sido reforzado por la historiografía contemporánea donde el estudio comparado entre la obra de Rousseau y El Pensador demuestra que la mayor parte de éste es una mera traducción de algunas páginas del libro I del Emilio. ${ }^{34}$ Esta misma dirección toma Negrin Fajardo cuando afirma:

La coincidencia de Rousseau y Clavijo es bastante amplia en el tema de la mujer. Clavijo se muestra más razonable, menos provocador que Rousseau, pero no deja de mantener una postura conservadora basada en el deseo de que la mujer de su tiempo volviese a ser la que ellos recordaban como ideal de un pasado mejor; era seguramente la nostalgia que sentían por la figura femenina que introyectaban en su infancia y que las costumbres dieciochescas perturbaban. ${ }^{35}$

33 ESPINOSA, Agustín, Don José Clavijo y Fajardo, Cabildo Insular, Las palmas de Gran Canarias, 1970. p.108.

34 Al respecto se puede consultar: NEGRIN FAJARDO, Olegario Estudios de la Historia de la Educación en Canarias, Cabildo Insular, Las Palmas de Gran Canaria, 1998 y SANTOS PUERTO, José "La penetración de Rousseau en España: El caso de El pensador, de Clavijo y Fajardo", Estudios franceses en memoria de A. Cioranescu, Isla Abierta, La Laguna, 2004, pp. 1249-1262

35 NEGRIN FAJARDO, Olegario Estudios de la Historia..., Op. Cit., p. 275. Citado en: SANTOS 
Por otro lado, en cuanto a materia educativa, percibimos en sus obras una clara correspondencia con el Emilio al defender la importancia de que las mujeres se hagan cargo de la educación primera de sus hijos. ${ }^{36}$ En Palabras del autor:

Los grandes, los señores, los ricos, y aun los que apenas logran una mediana fortuna, están en tranquila posesión de desembarazarse de sus hijos desde que salen del seno materno. Ve aquí un error enorme, error perjudicial para el estado, a la salud de la madre, diametralmente opuesto a sus mejores, y más sólidos derechos, y que casi la degrada de los fueros, y preeminencias de la maternidad...

Quisiera que me dijesen las madres para qué fin discurren que el autor de la naturaleza les ha dado estos medios... ¿Para dar más elegancia a su figura? ${ }^{37}$

Para el autor -al igual que para Rousseau- la educación que deben impartir los padres es fundamental. Así Clavijo critica la falta de juicio para la elección de los preceptores en los sectores altos de la sociedad donde parece primar el factor económico al de preparación o instrucción del maestro.

Es muy notable y digno de compasión, que un padre, que no perdona gasto alguno para procurar a sus hijos establecimientos brillantes, y que a costa de gastos excesivos les mantiene magníficos vestidos, y equipajes, y multitud de criados inútiles, solo conozca la economía cuando se trata de buscar, y atraer una o más personas que cultiven el espíritu de los mismo, los instruyan en la religión, planten en sus corazones las semillas del sano moral y de la buena política. ${ }^{38}$

Es claro que Clavijo lee y reinterpreta a Rousseau. Sin embargo, el español, rompe con la propuesta roussoniana al considerar que la educación es y debe seguir siendo una educación católica, desde la primera infancia a cargo de los padres. Al tiempo que proclama que el maestro debe ser "Un censor rígido de (la) conducta y un maestro ilustrado". ${ }^{39}$ Así,

PUERTO, José “La penetración...", Op. Cit.

36 En este sentido el Libro primero del Emilio es muy sugerente: "Es a ti a quien yo me dirijo, tierna y previsora madre que sabes apartarte de la carretera y garantizar al arbolillo naciente contra el choque de las opiniones humanas! Cultiva, riégala planta joven antes de que ella muera: sus frutos harán un día tus delicias. Forma a su hora un cerco en torno al alma de tu hijo; otro puede señalar el circuito pero tu sola debes alzar la barrera" ROUSSEAU, Jean-Jacques, Emilio ..., 1762. Libro 1, p 36.

37 CLAVIJO y FAJARDO, José, Antología de El pensador, Introducción de Sebastián de la Nuez, Islas canarias. 1989. Pensamiento XII: Sobre la educación, p. 105.

38 CLAVIJO y FAJARDO, José, El pensador, Imprenta de Joaquín Ibarra, Madrid, 1767. Pensamientos LXIII y LXIV: La educación de las clases pudientes, p. 185.

39 Ídem, p. 186 
el castigo se impone en la pedagogía de Clavijo, como forma de corrección, distanciándose de la propuesta del francés. ${ }^{40}$

\section{Enseñar desde la experiencia: Viera y Clavijo}

La preocupación por la experiencia en la educación ha sido algo constante en las propuestas ilustradas desde Locke en adelante. Rousseau siguiendo este pensamiento le brindo a la experiencia un lugar destacado en su pedagogía.

La influencia de autores como Locke, Voltaire, Montesquieu y Rousseau se expresa en el planteo político que Viera hace de la educación, pero también en cuestiones pedagógicas propias de la enseñanza. Así, para el ilustrado canario, existen dos cosas que se le deben encargar al maestro con mucho cuidado:

La una que no se presente desde luego la lectura a los niños, como un trabajo serio, pues ciertamente su edad no sufre esas formalidades; y la otra que no se enfade con ellos ni los castigue, aunque vea que no hacen unos progresos rápidos. La displicencia y el aire pedante de un maestro imprudente o precipitado es casi siempre la causa de aquel intimo disgusto que sienten regularmente los muchachos y que conservan toda la vida por lo que llaman ciencia y estudio. ${ }^{41}$

En este sentido la propuesta pedagógica de Viera se profundiza alcanzando claros caracteres revolucionarios dentro de la educación, similares a la pedagogía roussoniana. Al igual que Rousseau, parte del conocimiento desde la experiencia y de la motivación del alumno para la enseñanza. Como mencionamos anteriormente la experiencia y el descubrimiento del placer del niño son fundamentales en la pedagogía del francés. ${ }^{42}$ Así, Viera se distancia de Clavijo, no solo en el aspecto pedagógico, sino también al dejar como garante de la educación al estado, en lugar de la familia, de aquí también se desprende la influencia del influjo francés al pedir la intervención del gobierno en la educación, en el sentido que Rousseau le había otorgado a la educación Pública.

40 Dice Rousseau al respecto: "Ya he dicho lo suficiente para dar a entender que nunca es necesario infringir a los niños el castigo como castigo, sino que éste le debe llegar como una secuencia natural de su mala acción", ROUSSEAU, Jean-Jacques, Emilio..., Op. Cit., Libro II, p. 110.

41 VIERA Y CLAVIJO, José, El sindico Personero General, Cabildo Insular, Las Palmas, 1994 (1764), p. 84.

42 Rousseau defiende esta idea tomando como ejemplo la Geografía: “Queréis enseñar la geografía a este niño, y vais a buscar globos, esferas, mapas: ¡Cuánto aparato! ¿Por qué todas estas representaciones? Comenzad por enseñarle el objeto mismo, a fin de que él sepa al menos de que le habláis!". ROUSSEAU Jean-Jacques, Emilio..., Op. Cit., Libro II, p. 191. 


\section{Instrucción pública y formación integral: Jovellanos}

En los Diarios de Jovellanos, se observan alusiones frecuentes tanto de Rousseau, como de otros intelectuales franceses e ingleses. Se suele coincidir, afirma Negrin Fajardo, "en la influencia especial que Rousseau, Locke, Smith y Mably tuvieron en la conformación de su ideario pedagógico". ${ }^{43}$

Podemos comparar dos aspectos fundamentales en los que pareciera verse la influencia roussoniana, estos son: la instrucción pública y la formación integral del hombre. En cuanto a la instrucción pública, podemos decir que -al igual que otros- postulaba la sustitución de los poderes eclesiásticos por los estatales, que debían ocuparse de una educación pública y universal, con el fin de desarrollar cultural y económicamente a la sociedad española. Siguiendo el principio enciclopedista del ilustrado francés, se pregunta en sus Memorias si la educación pública es el origen de la prosperidad social, arribando a la conclusión de que la misma reclama una formación a los derechos y deberes del ciudadano, aspirando a formar miembros de la sociedad y sujetos de derechos. ${ }^{44}$

Por otra parte, propone una educación integral que se apoye en el humanismo pedagógico, al tiempo que instruya en artes y oficios. Desde esta perspectiva la reforma educativa de este ilustrado defendía, al igual que Campomanes, ${ }^{45}$ la necesidad de enaltecer la figura del artesano como una persona honorable. El honor estaría dado por el respeto que pudiera conseguir en el lugar que a cada uno le toca en la sociedad. En este sentido debemos recordar, una vez más, la necesidad del tutor de Emilio de educarlo en un oficio que aunque nunca lo vaya a ejercer, le ayude a estar prevenido.

Sin embargo, Jovellanos rompe con la propuesta roussoniana al integrar la religión. Dice en su Memoria sobre la educación pública: "el objeto general de toda instrucción se cifra en el conocimiento de Dios, del Hombre y de la naturaleza". ${ }^{46}$ Así la renovación pedagógica se ve frenada por la profesión de fe del ilustrado, con la cual la propuesta de Rousseau no condice.

\section{El problema de la educación femenina: Pedro de Montengón}

El Eusebio de Montengón es quizás uno de los trabajos que más ha sido comparado con el Emilio. Los trabajos de literatura comparada revelan ideas y planteos similares que

43 NEGRIN FAJARDO, Olegario, Historia de la educación española, UNED, Madrid, 2006, p. 172.

44 Ibídem.

45 RODRÍGUEZ de CAMPOMANES, Pedro, Discurso sobre el fomento de la industria popular, Imprenta de Antonio Sancha, Madrid, 1774.

46 JOVELLANOS, Gaspar, Memoria sobre la educación pública o tratado teórico-práctico de enseñanza, Rivadeneyra, Madrid, 1802, T. XLVI. p 239 
pueden tener su origen en la remembranza que ambos autores hacen de clásicos como Epicteto y Séneca. ${ }^{47}$

Las discusiones en torno a la figura de la mujer durante la ilustración y las producciones discursivas al respecto ha sido ampliamente trabajados por la historiografía que abordó las cuestiones de género, en este sentido sólo señalaremos aquí la construcción que ambos autores hacen del ideal de feminidad asociado a la maternidad y a la crianza. ${ }^{48}$

El análisis de Montengón invierte el orden del análisis roussoniano. En el Emilio la educación del niño aparece claramente expuesta en el primer apartado de la obra; mientras que en el texto español, ésta aparece como el resultado de la necesidad de Eusebio de educar a su hijo, en el último tomo de la obra.

El tema antes trabajado de la defensa al amamantamiento de las madres y al cuidado y educación de los padres en primer lugar hacen creer que la cuarta parte del Eusebio es casi la traducción del primer capítulo de la obra de Rousseau. Sin embargo, esta dependencia y la afección por bregar por el cuidado familiar es, como dijimos, fácilmente rastreable en toda la literatura Ilustrada de la época desde Locke en adelante. Así, ambos autores reconocen de vital importancia la educación del niño por los propios padres por lo menos desde su nacimiento hasta entrados los dos años donde el infante ya aprenda a jugar y valorar las cosas que le interesan. Dice Eusebio a Leocadia al respecto:

El hijo no puede tener mejor maestro que el padre ni debieran tener otros los hijos. Mas ¿Cuántos hay que conozcan y ejerciten esta obligación que la naturaleza les impone? Las mismas madres hacen traición a la más pura ternura de su afecto, para eludir la incomodidad de criar a sus pechos los hijos ${ }^{49}$

Ambos autores coinciden en la necesidad de educar a los tutorados en un oficio a fin de que cuando las aceche la desgracia este preparado para afrontarla. Nada depreciable es el horror y la congoja con que las madres de Emilio y Eusebio recibirán la propuesta de los preceptores de una educación artesana. Así por ejemplo proclama la madre de Emilio: “¡Un Oficio mi Hijo! ¡Mi hijo artesano! Señor en que estáis pensando?”. ${ }^{50}$ La misma Susana

47 Ver por ejemplo: BANNAN; Edward, Dos novelas pedagógicas de Montegón y sus relaciones con Rousseau, (Tesis) Universidad de Madrid, 1932; ISAAC, Jeanne, Les vicisitudes de 1786 a 1851 de un roman rousseauiste en Espagne: "Eusebio" de Pedro Montengon, (Tesis) Universidad de Burdeos III, 1978; Ambas citadas en GARCÍA LARA, Fernando, Introducción al Eusebio, Editora Nacional, Madrid. SANTOJA, Pedro, El "Eusebio" de Montengón y el "Emilio" de Rousseau: el contexto histórico (trabajo de literatura comparada,) Alicante, CSIC, 1994.

48 Sobre el tema se puede consultar: MOLINA PETIT, Cristina, Dialéctica feminista de la educación, Barcelona, Anthropos, 1994.

49 MONTENGON, Pedro, Eusebio, Casa de Mason e hijo. Paris, 1824, Cuarta parte, p. 200

50 ROUSSEAU, Jean-Jacques, Emilio..., Op. Cit., Libro III, p. 224 
tendría un arrebato semejante ante la propuesta de Hardyl. ${ }^{51} \mathrm{Al}$ pesar de ambas madres, las familias terminan cediendo a la educación propuesta por los tutores. Situación ante la cual Emilio aparece más pasivo que Eusebio quien se muestra indignado por el oficio que le tocó en suerte y protestando se manifiesta en contra, aunque termina por acostumbrarse. Así cuando Susana le pregunta por él, el mismo niño termina respondiendo: "Poco a poco me iré acostumbrando; el tiempo y la necesidad me lo harán más llevadero de lo que hubiera pensado". 52

Por otro lado, el rol de la mujer en ambas obras es por momentos diferente, Leocadia (Mujer de Eusebio) no es una copia fiel de Sofía, tienen particularidades y diferencias en torno a la educación. La mujer ejemplar de Rousseau es una mujer cuya educación esta dada a partir de su lugar al lado del hombre, que tiene manejo de lectura, que conoce muy bien las artes de la casa y que posee religión, sencilla "Pocos dogmas y menos practicas que devoción", ${ }^{53}$ pero fundamentalmente fiel.

Leocadia, en cambio, no posee mucha instrucción es Eusebio quien después de casados deberá instruirla en la moral, la virtud y la región dado que ella desconoce hasta el Evangelio. Esta mujer, también desconoce criterios prácticos, siendo su marido quien debe orientarla sobre cómo amamantar o fajar al bebe.

Finalmente, Leocadia aparece con un rol más activo en la obra que el de Sofia, ésta es menos sometida al marido y menos sumisa, distinta a la actitud que la mujer de Emilio tiene para con este.

Ambos trabajos presentan un mismo problema de modo distinto. Mientras en el texto español la novela deja entrever los lineamientos pedagógicos; por el contrario, el texto francés es el tratado pedagógico el que deja entrever la novela.

\section{Educación y Revolución: Francisco Cabarrús}

Francisco Cabarrús es, con todo, el más revolucionario de los ilustrados españoles, él ve a la educación como necesaria para el progreso de las luces y como medio para que el cambio de la sociedad opere pacíficamente.

Para el autor, la educación -que es todo lo que le pasa a uno desde que nace hasta que muere- debe fomentar el patriotismo, el sentimiento nacional, de pertenencia a la comunidad política, la adhesión al Estado, así como los sentimientos morales. Propone una educación específicamente política, para la que es necesario que se publique y se imponga un "catecismo político". ${ }^{54}$ Se trata de difundir los conceptos fundamentales sobre la sociedad que

51 "Con todo Susana dió quejas a su marido mostrándose resistir a una educación tan extravagante" MONTENGÖN, Pedro. Eusebio, Sierra y Martin, Barcelona, Primera parte, 1793, p. 23

52 Ídem, p. 39

53 MONTENGON, Pedro, Eusebio..., Op. Cit., p. 459

54 CABARRÚS, Francisco de, "Sobre los obstáculos que la naturaleza, la opinión y las leyes a la 
han de ser patrimonio común de todos los ciudadanos. Es un proyecto de enseñanza laica, gratuita, igualitaria y obligatoria. ${ }^{55}$

En sus Cartas, retomando a Rousseau, Cabarrús propone una educación gradual, donde las etapas en la educación son fundamentales. El niño desde que nace es capaz de razonar, sin embargo, el origen de este razonamiento es sensible no intelectual, por ello, dependerá exclusivamente de las capacidades de los educadores el éxito o el fracaso de la enseñanza. En este sentido, debe el tutor tener como base la experiencia, algo que ya habíamos mencionado como clave para el caso de otros intelectuales españoles.

Para Cabarrús la educación deberá orientar a los niños según su vocación desde de los 10 años, teniendo en cuenta las necesidades del Estado, así se privilegian los oficios necesarios: agricultores, artesanos, industriales y comerciantes, dándose menos lugar al estado religioso, la milicia, la jurisprudencia y a todas aquellas clases de procuradores, agentes de oficina y criados. ${ }^{56}$ Esto también lo vemos refrendado en el citado pasaje del Emilio en el que Rousseau defiende la formación en diferentes artes "para la vida".

El proyecto de este ilustrado es un proyecto verdaderamente revolucionario parece comprender la totalidad de la obra roussoniana y se dispone a llevarla a la práctica desde la reforma, con el fin de evitar la sangrienta experiencia de Francia en 1789.

\section{Conclusión}

Al empezar el trabajo citábamos un fragmento del Emilio donde Rousseau manifestaba sus reticencias a implantar el modelo pedagógico en otro contexto diferente al francés. En la misma dirección, Bourdieu afirma que los textos circulan sin sus contextos, es decir sin su campo de producción y que al insertarse en un campo de producción diferente se resignifican. ${ }^{57}$ El proceso de apropiación que ha trabajado Chartier ${ }^{58}$ en función de las lec-

felicidad pública"; 1795, en DE OCHOA, EugENIO (compilador), Biblioteca de autores españoles, desde la formación del lenguaje hasta nuestros días. Epistolario español. Madrid, 1870. T. II. Carta segunda, p. 570.

55 Quizás los dos términos que generen más controversias en esta afirmación sean los de Laicidad e igualdad: En cuanto al primero el autor es muy claro al respecto, la religión no debe formar parte de la educación, ya que la instrucción debe estar abocada a la construcción de ciudadanos que respeten los ideales políticos. Por otro lado, el término igualdad hace referencia al intento de instituir tanto a ricos como a pobres de forma igual y simultánea, a fin de conformar en todos una conciencia política de unidad y respeto al gobierno. PERRUPATO, Sebastián, "Pedagogía y crítica en el siglo XVIII español. La obra de Francisco Cabarrús", en GONZÁLEZ MEZQUITA, María Luz (coordinadora), Historia Moderna, Viejos y Nuevos problemas, Eudem, Mar del Plata, 2009.

56 CABARRÚs, Francisco de, Cartas..., Op. Cit.

57 BOURDIEU, Pierre, “Las condiciones sociales...",Op. Cit., pp. 2 y 3

58 CHARTIER, Roger, El Mundo..., Op. Cit. 
turas, nos permite apreciar la complejidad de un fenómeno que se apropia de un discurso extranjero pero que al mismo tiempo, como todo proceso de apropiación, lo reelabora y le da nuevo sentido.

La realidad española era, sin dudas, algo distinta a la francesa, los historiadores han querido ver en esta diferencia -dada, entre otras cosas, por la religiosidad- un elemento de autenticidad para la construcción de un siglo ilustrado español. Sin embargo, el cruce de la obra de Rousseau con otras obras españolas, nos revela que mucho es lo que dista esta realidad de ser cierta. España -como gran parte de Europa- atravesaba en este siglo por una crisis de la cual era necesario salir. En este sentido

Si la sociedad estamental del antiguo régimen y el sistema educativo y filosófico tradicional se oponían a las reformas era imprescindible eliminarlos, como se propuso en las diversas fases de la revolución francesa, o transformarlos como defendía la versión española ilustrada representada entre otros por Jovellanos o Campomanes. ${ }^{59}$

No podemos decir exactamente hasta qué punto las propuestas ilustradas españolas deben su influjo al genio francés o si, por el contrario, solo son el resultado de las relecturas de autores clásicos y modernos que tanto Rousseau como los españoles conocían muy bien. En este sentido debemos reconocer la labor que los Novatores han hecho en materia educativa. Feijoo, Corachán, Cabriada y Mayans entre otros, se han convertido en un reverbero en el cual la generación de ilustrados pudo ver sus antecedentes.

Podemos decir, en cambio, que los ilustrados españoles del siglo XVIII leen y reinterpretan a Rousseau, pero no solo a él. Las propuestas de principio de siglo y los caracteres propios del contexto español, hacen necesaria una redefinición de la obra del ilustrado francés que muchas veces poco es lo que se ajusta a su sentido original, en la comprensión del carácter revolucionario y utópico del Emilio.

Con todo es quizás Cabarrús quien mejor ha interpretado y adoptado el modelo del Emilio, pero justamente es por ello que su obra tiene más de francesa que de española; muchas veces este ilustrado parece no tener en cuenta el contexto que lo rodea y pierde así las características propias de una Ilustración que aunque, infiltrada por lo francés, responde a caracteres españoles que tienden a reproducirse en el resto de Europa por medio de la “circulación de ideas". Sin embargo, este tema aún está por estudiarse y nadie, por lo que se conoce, ha destacado hasta que punto podemos hablar de la influencia de los ilustrados españoles en las obras de Francia, de Inglaterra o del resto de Europa.

Podemos, a modo de síntesis, recapitular el cruce de la propuesta española con la obra de Rousseau en torno a cinco cuestiones, que aunque desiguales -ya que no son tomadas del mismo modo por todos- encarnan los análisis comparativos y la dirección de la investigación presentada.

1) Tanto los ilustrados españoles analizados aquí como Rousseau, proponen una edu- 
cación para la vida, la necesidad de formar al pueblo en actividades útiles para el reino parece una constante en varios de los intelectuales que, por medio de reformas, intentan salvar a España de la profunda crisis.

2) Todos los intelectuales estudiados parecen beber en las mismas aguas al afirmar que el origen del conocimiento se basa en la experiencia y que la educación debe partir de las necesidades e inquietudes del educando. Este postulado, sin dudas Lockeano, atraviesa las obras de los doctos españoles y del mismo de Rousseau.

3) El descubrimiento roussoniano del niño y de la gradualidad en su aprendizaje, parece coincidir con el de muchos ilustrados que repiensan la educación orientándola según las edades de los infantes. Estableciendo como deber del preceptor, fundar una relación directa entre el estadio de desarrollo del niño y su educación.

4) La educación de la mujer debe estar fundamentalmente abocada a la familia y a su lugar en torno al hombre, incluso el más revolucionario de los autores españoles no se apartara de la idea roussoniana de educar a las mujeres para que sean funcionales al hombre. Sin embargo, es de nuestro parecer que la idea de familia burguesa a la que adhiere Rousseau y sobre la que tanto hincapié hemos hecho en párrafos anteriores no es del todo consonante con la idea de familia propia de los ilustrados españoles que, más fieles a la tradición, prefieren un modelo familiar noble con características notablemente distintas. Un gran ejemplo de ello lo encontramos en la comparación del modelo familiar de Emilio con el de Eusebio.

5) Quizás el planteo más radical de Rousseau llegue con en la idea de la necesidad de una educación pública que esté en manos del Estado, apartada de la Iglesia y orientada fundamentalmente a formar ciudadanos. En este sentido, vemos una divisoria de aguas en los desarrollos españoles: por un lado, contamos con propuestas que no alejan la instrucción de la fe católica, el mismo Jovellanos a pesar de creer que la educación debe ser impartida por laicos termina aceptando dejarla en manos del Clero. ${ }^{60}$ Los españoles dieciochistas se cuidaron mucho de no entrar en coalición con la Inquisición. Pese a ello encontramos propuestas como la de Cabarrús que creen firmemente en la laicidad de la enseñanza e intentaran apartar a la Iglesia de la educación por todos los medios posibles.

Se establece en estos cinco puntos un acercamiento entre las propuestas españolas y la del ginebrino. Sin embargo, éstas se distancian al adaptarlos, como dijimos anteriormente, en un contexto español diferente al del resto de Europa, desentendiendo como dice Rousseau que "tal educación puede ser practicable en Suiza y no serlo en Francia."

60 JOVELLANOS, Gaspar, "Informe de la sociedad económica de Madrid al Real y Supremo Consejo de Castilla en el expediente de ley agraria”, en PEÑALVER SOMO, Patricio, Jovellanos obras sociales y políticas, Publicaciones Españolas, Madrid, 1962.

61 ROUSSEAU; Jean-Jacques, Emilio..., Op. Cit., p. 33 
Entre el naturalismo y la tradición es entonces, la característica de una ilustración, la española, que pretende incorporar la pedagogía moderna-encarnada por Rousseau-pero que se niega a abandonar los cánones tradicionales sobre los que se asienta la sociedad. Existe sin dudas aún una preocupación por una educación elitista y estamental, que se advierte en las propuestas del Seminario de Nobles de Vergara, pero esta preocupación va dando paso a una educación más popular dirigida a la los ideales de un primitivo liberalismo que recién comienza a gestarse.

Recibido: $14 / 04 / 2012$

Aceptado: 31/07/2012 